\title{
Prevalence of and Factors Associated with Work Stress
}

\section{in Academia in Tanzania}

\author{
Kitila Mkumbo ${ }^{1}$ \\ ${ }^{1}$ Faculty of Education, Dar es Salaam University College of Education, P O Box 2329, Dar es Salaam, Tanzania \\ Correspondence: Kitila Mkumbo, Faculty of Education, Dar es Salaam University College of Education, P O Box \\ 2329, Dar es Salaam, Tanzania. Tel: 255-22-285-0158/255-754-301-908. E-mail: kitilam@udsm.ac.tz
}

Received: July 1, 2013

Accepted: August 30, 2013

Online Published: September 12, 2013

doi:10.5430/ijhe.v3n1p1

URL: http://dx.doi.org/10.5430/ijhe.v3n1p1

\begin{abstract}
Work stress has been identified as a common phenomenon in the teaching profession. However, little research has been done to examine the prevalence of and factors associated with work stress among employees in university context in Tanzania and sub-Saharan African countries in general. Using survey design within the quantitative approach, this study investigated the prevalence of and factors causing work stress among academic staff in public and private universities. The results show that a significant proportion of academic staff reported experiencing high stress, with respondents in public universities reporting being more stressed than their counterparts in private universities. Three factors have been identified as particularly associated with work stress among academic staff. These are lack of staff involvement in institutional reform processes, lack of necessary support systems related to their work and high workload levels. Highly qualified and experienced staff reported lower levels of stress than staff with low qualifications and less experienced. These results indicate that work stress is a common phenomenon among institutions of higher education with its associated consequences such low job satisfaction, which is likely to affect staff's productivity.
\end{abstract}

Keywords: Academia, Physiological stress, Psychological stress, Private university, Public university, Tanzania

\section{Background}

According to Dunham (1992), there are three perspectives that can be used to explain the phenomenon of stress. The first perspective defines stress from an engineering perspective, deriving its meaning from the Hooke's Law of Electricity, which states that "if the strain produced by a given stress falls within the 'elastic limit' of the material, then when the stress is removed the material will simply return to its original condition. If, however, the strain passes beyond the "elastic limit, then some permanent damage will result" (Dunham, 1992, p.1). The model suggests that people, too, have their limits. Up to a point, stress can be tolerated, but when it becomes intolerable, damage may result, either psychological, physiological or both. This perspective sees stress as a set of causes, rather than a set of symptoms. This approach has been criticized on the basis that it does not take into account individual differences, and for treating people like machines, which is too simplistic given the complexity of human beings.

The second approach defines stress with respect to the reactions individuals produce in response to pressures exerted on them. These reactions may be expressed in form of physical or emotional manifestations. They include such reactions as headaches, muscular tensions and stomach ailments, anxiety, frustrations, etc.

The third approach takes an interactionist approach in which both pressures and reactions are taken into account, as well as coping resources available. Stress from this perspective is therefore seen as a significant excess of pressures over coping resources. This approach emphasises the importance of identifying the demands, which individuals perceive, and experience as stressful and the behaviour they use to tackle these demands.

Indeed many writers view 'stress' as an elusive concept whose definition is confusing, though it appears superficially clear to both professionals and laypeople (Ayers et al., 2007). This is why Maslach et al (2001) opted for a less confusing term, namely burnout. According to them burn out is a prolonged response to chronic emotional and interpersonal stressors in the job, and is defined by three dimensions, namely exhaustion, cynicism and inefficacy. In the context of this study both terms are used interchangeably and synonymously. 
Work related stress is common in many organisational contexts. Work related stress refers to stress caused by or made worse by work. It occurs when a person perceives the work environment in such a way that his or her reaction involves feelings of an inability to cope (Health and Safety Authority, 2011). The UK's Health and Safety Executive (HSE, 2006) has identified six categories of work related stress, namely demands, control, relationships, change, role and support. According to HSE, workload is the most pervasive factor linked to work related stress. Work related stress occurs when there is a mismatch between the demands of the job and the resources and capabilities of the individual work to meet those demands (Blaud, Kenyon \& Lekhi, 2007).

Studies show that the education sector is one of the stress ridden work settings (Galloway et al., 1990; Nhundu, 1999; Phillips, Sen \& McNamee, 2007; Palmer \& Cooper, 2007). For example, a study in the UK revealed that the prevalence of stress among principals and head teachers was significantly higher than among workers in other sectors (Sheena et al., 2005). Further, studies have shown that, by their nature, academic staff and other people working in university settings can easily be prone to occupational stress (Redhwan, et al., 2009). A study conducted by the Keil Centre for the Health and Safety Executive (HSE, 2006) involving about 300 professions revealed that individuals working in teaching reported the highest stress.

Although a high level of stress has been observed in teachers generally, the higher education sector is a relatively new focus of concern. There is strong evidence to believe its workforce could represent a particularly vulnerable occupational group. For example, in Malaysia, a study involving 300 members of academic staff in one university reported that job stress was one of the significant factors reducing job satisfaction among staff (Ahsan, Abdullah, Fie \& Alam, 2009).

In 1994, Blix, Cruise, Mitchell and Blix reported that 66 percent of a large sample of university lecturers perceived severe levels of stress at work at least 50 percent of the time. These authors concluded that most of the stress experienced by the respondents related directly to limited resources or shortage of time. There were, however, other causes for concern within the profession, including slow progresses in career advancement, poor faculty communication, professional disillusionment and inadequate salaries. Additional sources of academic pressure identified in the literature include heavy workload, role ambiguity, conflicting job demands, frequent interruptions, and striving for publication (Winefield \& Jarret, 2001). Further studies have concluded that a significant proportion of stress experienced by academics is likely to emanate from the competing demands of career and family life, and long working hours (both on and off campus) (Sorcinelli \& Gregory, 1987).

A survey on stress and job satisfaction in academic staff conducted by Abouserie (1996) in a Welsh university also highlighted the existence of high levels of stress in academic staff: 74 percent of respondents reported moderate levels of stress, and 10 percent fell into the 'serious stress' category. Seventy-four percent of respondents rated work as the most significant source of stress in their lives, and 40 percent stated that conducting research was the main cause of stress when at work, followed by time constraints (39 percent), relationships with colleagues (27 percent), teaching (19 percent), administration (19 percent), and demands from students (15 percent). Again, lecturers from the lower grades reported the most extreme levels of occupational stress.

A study by Fisher (1994) in two Scottish universities also indicated that psychological stress is a feature of occupational life for university staff. An increasing number of academics in higher education institutions have to perform a number of roles simultaneously: the job commonly involves teaching, planning and running tutorials, laboratories and seminars and dealing with students' personal problems, whilst at the same time carrying out research, conducting personal experiments, attempting to obtain research funding, writing papers and books and attending conferences. Under such conditions, the potential for role overload and role conflict is high. A multiplicity of roles, each with numerous factors regularly competing for attention, are potentially strain-producing for the individual, and potentially damaging for the quality of work undertaken, for example in teaching and research. Research into the antecedents and outcomes of occupational stress has indicated that role-stress can have a number of undesirable effects on the well-being of the individual and his or her working life: for example, increased job tension, lower job satisfaction and reduced confidence in the employing organisation (Kahn, 1974).

There is dearth of studies about stress in work settings in developing countries in general and in Tanzania in particular. Little is, therefore, known about the prevalence and possible sources of stress among employees in different work settings. This study sought to address this gap in knowledge by assessing the level and sources of stress among staff in higher education work settings. The study sought to contribute to better understanding of work-related stress among staff in selected higher education institutions in Tanzania. More specifically, the study aimed to assess the prevalence of stress among academic staff; investigate the possible sources of stress among 
academic staff; and examine the relationship between working conditions, demographic factors and stress and stress coping strategies among staff in higher education institutions

\section{Method}

A survey design was employed in this study. Respondents completed a six-part questionnaire assessing their potential exposure to stress related conditions. Part I consisted of items on participants demographic information such as age, sex, job position, level of seniority, etc. Part II consisted of 12 items on working conditions. Part III comprised 21 items on stress symptoms. Part IV comprised 9 items assessing workload. Part V comprised items assessing factors causing work related stress. These were divided into six categories, namely demand, control, relationships, role, change and support. The last section consisted of two open general items asking participants to provide their opinion on how to address causes of work related stress. In line with Ismail, Yao and Yunus's (2009) view of occupational stress, the questionnaire was further categorized into two major parts capturing physiological and psychological stress. The physiological stress part consisted of 18 items and the psychological stress part consisted of eight (8) items.

The questionnaire was adopted from the occupational stress survey about experiences of occupational stress among academics in higher education in the UK, which was also developed from the Health and Safety Executives' Management standards indicator tool (Court \& Kinman, 2008). The reliability of the tool was good with items having a Cronbach's coefficient of more than 0.70 .

Participants were drawn from two public universities and two private universities, which were purposively selected. The public universities involved one old university, namely University of Dar es Salaam (UDSM, located in the Commercial Capital of Tanzania, Dar es Salaam), and one newly established university, namely University of Dodoma (UDOM, located in the Capital City in the central part of Tanzania). Similarly, one old private university and one newly established university were selected. These were the Tumaini University College in Iringa (located in southern part of Tanzania) and the St. Johns University in Dodoma.Within the institution, the list of all academic staff was obtained. From this list, an appropriate sample was drawn using the computer table of random numbers.

In determining the appropriate sample size, a table of sample size determination developed by Bartlett, Kotrik and Higgins (2001) was used. Barlett's et al. table works for the study that uses both continuous and categorical independent variables and whose margin of error is set between .03 and .05 , which was the case in this study. Accordingly, it was approximated that the number of both academic staff in the four participating institutions was about 2,500. According to Barlett et al. (2001), the recommended sample size for a study involving participants drawn from a population size of between 2000 and 4000 is 499 and 570 respectively. Accordingly, the sample size for this study was set at 499

\subsection{Data Management and Analysis}

Data collected in this study were entered and analyzed quantitatively using the SPSS version 17.0 programme (Pallant, 2005). Prior to data entry and analysis, the questionnaire was carefully coded. To check consistency in data entry, a frequency run was carried out for all variables to check any values that may have been entered wrongly and inconsistently.

Prevalence of stress was established by using frequency counts and percentages. Possible sources of stress were derived by frequency counts and percentages, as well as confirmatory factor analysis.

The correlates of stress were established at two levels. Firstly, an independent samples t-test was carried out to investigate the sex differences in the prevalence of stress. Secondly, a one-way between groups analysis of variance (ANOVA) was conducted to explore the variation in the prevalence of stress among the different staff groups (senior vs. junior, experienced vs. inexperienced, etc). Thirdly, multiple regression analysis was conducted to examine the possible associations between participants' demographic characteristics (such as age, sex, staff category and family characteristics).

\section{Results}

\subsection{Participants characteristics}

A total of 326 respondents completed the questionnaire (a response rate of $65 \%$ ). The respondents' age ranged between 23 and 69 years, with a mean age of 40.1 years $(\mathrm{STD}=9.1)$. The majority of the respondents aged 30-40 $(40.8 \%)$ years and $41-50$ years $(34.5 \%)$. More than two thirds $(68.7 \%)$ of the respondents were female, and the majority of the respondents (52.4\%) were at the senior academic level (holding a Ph.D. and an academic rank of a lecturer and above). The respondents' profile is summarised in Table 1. 
Table 1. Respondents' Profile

\begin{tabular}{|c|c|c|c|c|c|c|c|}
\hline \multirow[b]{2}{*}{ Demographic } & \multicolumn{7}{|c|}{ Institution (\%) } \\
\hline & $\begin{array}{c}U D S M \\
(N=217)\end{array}$ & $\begin{array}{l}U D O M \\
(N=66)\end{array}$ & $\begin{array}{c}\text { Tumaini } \\
(N=14)\end{array}$ & $\begin{array}{c}\text { St Johns } \\
(N=29)\end{array}$ & $\begin{array}{c}\text { Public } \\
(N=283)\end{array}$ & $\begin{array}{l}\text { Private } \\
(N=43)\end{array}$ & $\begin{array}{l}\text { Overall } \\
(N=326)\end{array}$ \\
\hline \multicolumn{8}{|l|}{$\underline{\text { Age }}$} \\
\hline$<30$ & 4.2 & 36.1 & 0.0 & 26.9 & 12.7 & 19.4 & 13.5 \\
\hline $30-40$ & 35.3 & 47.5 & 50.0 & 57.7 & 38.6 & 55.6 & 40.8 \\
\hline $41-50$ & 49.1 & 11.5 & 20.0 & 3.8 & 39 & 8.3 & 34.5 \\
\hline $51-59$ & 8.4 & 1.6 & 20.0 & 7.7 & 6.6 & 11.6 & 7.5 \\
\hline$>=60$ & 3 & 3.3 & 10.0 & 3.8 & 3.1 & 5.6 & 3.7 \\
\hline \multicolumn{8}{|l|}{$\underline{\operatorname{Sex}}$} \\
\hline$\overline{\text { Male }}$ & 64.8 & 75.8 & 80 & 73.1 & 67.4 & 75.0 & 68.7 \\
\hline Female & 35.2 & 24.2 & 20.0 & 26.9 & 32.6 & 25.0 & 31.3 \\
\hline \multicolumn{8}{|l|}{ Level of Seniority } \\
\hline Senior & 67.9 & 12.9 & 40.0 & 50.0 & 52.7 & 46.2 & 52.4 \\
\hline Junior & 32.1 & 87.1 & 60.0 & 50.0 & 47.3 & 53.8 & 47.6 \\
\hline \multicolumn{8}{|l|}{$\underline{\text { Respondents' }}$} \\
\hline \multicolumn{8}{|l|}{$\overline{\text { specialisation }}$} \\
\hline \multicolumn{8}{|l|}{$\underline{\text { area }}$} \\
\hline $\begin{array}{l}\text { Social sciences } \\
\text { and humanities }\end{array}$ & 22.4 & 66.0 & 83.3 & 100.0 & 41.0 & 90.0 & 44.5 \\
\hline $\begin{array}{c}\text { Engineering and } \\
\text { sciences }\end{array}$ & 77.6 & 34.0 & 16.7 & 0.0 & 59.0 & 10.0 & 55.5 \\
\hline \multicolumn{8}{|l|}{ Work experience } \\
\hline Less than 5 & 20.6 & 95.5 & 50.0 & 96.2 & 38.5 & 83.3 & 43.2 \\
\hline \multirow{3}{*}{$\begin{array}{c}\text { years } \\
\text { 5-9 years } \\
10-20 \text { years } \\
\text { More than } 20 \\
\text { years }\end{array}$} & 33.5 & 4.5 & 40.0 & 3.8 & 26.5 & 13.9 & 25.6 \\
\hline & 41.1 & 0.0 & 10.0 & 0.0 & 31.3 & 2.8 & 27.8 \\
\hline & 4.8 & 0.0 & 0.0 & 0.0 & 3.6 & 0.0 & 3.5 \\
\hline \multicolumn{8}{|l|}{$\begin{array}{l}\text { Employment } \\
\text { mode }\end{array}$} \\
\hline $\begin{array}{c}\text { Fulltime with a } \\
\text { permanent } \\
\text { contract }\end{array}$ & 91.1 & 93.9 & 80.0 & 61.5 & 91.8 & 66.7 & 89.1 \\
\hline $\begin{array}{c}\text { Fulltime with a } \\
\text { fixed contract }\end{array}$ & 8.9 & 6.1 & 20.0 & 38.5 & 8.2 & 34.3 & 10.9 \\
\hline
\end{tabular}

\subsection{Working conditions}

To assess their views about working conditions, respondents were provided with 10 statements related to their level of satisfaction to various working conditions, and they were asked to response affirmatively or in negation. In general, a majority of respondents seemed to be quite contended with their working conditions. However, a close examination of their responses to a few conditions indicated that their level of satisfaction was quite low, particularly among staff in private universities. 
For example, while 67.1 percent of the respondents in public universities reported having been promoted in the past three years, only 19.4 percent of the respondents in the private universities reported as such and the variation was statistically significant. This indicates that the rate of promotion, an important attribute of job satisfaction, in private universities may be slower than in public universities. Again, a statistically significantly higher proportion of respondents in private universities $(78.8 \%)$ felt that their level of responsibility had increased in the past three years than respondents in the public universities $(57.1 \%)$.

When asked would you choose a different career if you had such an opportunity, 44.5 percent of the respondents in the public universities responded in affirmative compared to 34.4 percent of the respondents in the private universities. The proportion of respondents reporting that they would choose a different career was highest for UDSM (45.5\%) followed by Tumaini (39.3\%), UDOM (39.1\%) and St Johns (34.8\%). This is clearly related to qualifications. Because respondents at the University of Dar es Salaam were highly qualified compared to their colleagues at other universities, they felt that they would easily secure another opportunity elsewhere given a chance.

Overall, a higher proportion of respondents in private universities reported higher level of satisfaction of their job compared to respondents in public universities. Sixty three percent of the respondents in private universities reported being satisfied with the working conditions of their institutions compared to 55 percent of their colleagues in public universities. However, this variation was not statistically significant: $\mathrm{X}^{2}(\mathrm{~N}=310,4)=6.70, p=.153$.

When data of the level of satisfaction were analysed by institution, the results showed that respondents at St Johns University (72\%) expressed the highest levels of satisfaction followed by respondents at UDOM (62.6\%), UDSM $(52.8 \%)$ and respondents at Tumaini University $(40 \%)$ were the least satisfied of their working conditions (see Figure $1)$.

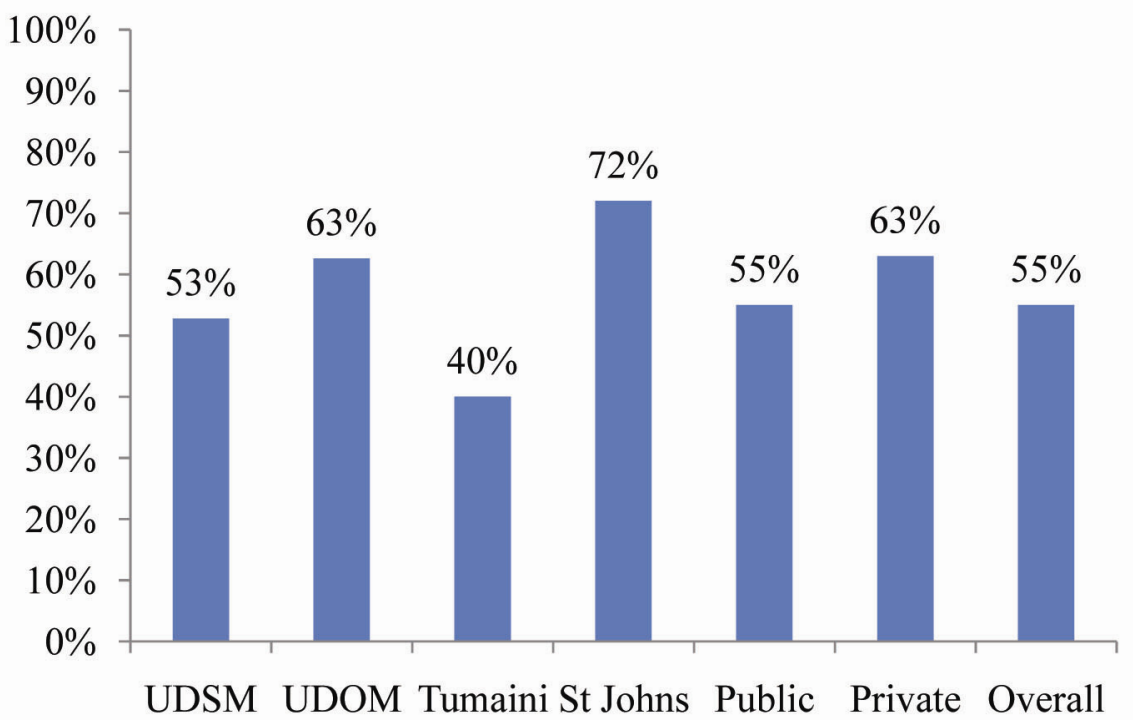

Figure 1. The proportion of respondents reporting that they're satisfied with the working conditions of their institutions

\subsection{Physiological and psychological stress experiences}

Occupational stress is commonly viewed as having two dimensions, namely physiological stress and psychological stress (Ismail, Yao \& Yunus, 2009). Physiological stress involves bodily reactions, such as headache, migraine, abdominal pain, body exhaustion, fatigue, heart palpitation etc. Psychological stress involves emotional reactions to a situation and may manifest itself in different forms, including, for example, anxiety, depression, job alienation, isolation, hostility, tension, anger, aggression, nervousness, inability to concentrate, frustration, etc. In this study, both of these dimensions were assessed and the results are presented below.

\subsubsection{Physiological stress}

The questionnaire consisted of 18 items on physiological stress. In each item, respondents were asked if they had ever experienced any of the states in the past 12 months on a three response option: 'never', 'sometimes' and 'often'. The responses are summarised in Figures 2 and 3. As Figure 2 shows, the majority of respondents (75\%) expressed 
that they had experienced physiological stress. The highest proportion of respondents reporting physiological stress came from UDSM (79\%) and UDOM (73\%). Respondents in private universities reported the lowest of physiological stress, with only 28 percent of respondents at Tumaini University and 39 percent of respondents at St Johns reporting having experienced physiological stress 'sometimes' last year.

The most commonly reported (reported by more than $60 \%$ of respondents) physiological related stress reactions were headache, aches and pains, indigestion and heart diseases.

Overall, about a quarter of the respondents reported high stress, with respondents in public universities reporting the highest levels of stress. More than two-thirds (68.1\%) of employees in public universities reported either being physiologically moderately stressed (40\%) or highly stressed (28.1\%). As Figure 3 shows, the highest proportion of respondents reporting being highly physiologically stressed came from UDOM (34.7\%), followed by UDSM (26.5\%). Chi square tests revealed a statistically significant difference in the level of physiological stress between public and private universities: $\mathrm{X}^{2}(284,2)=22.49, p<.00005, P h i=.28$, as well as between institutions: $\mathrm{X}^{2}(284,6)$ $=27.48, p<.00005$, Phi $=.31$.

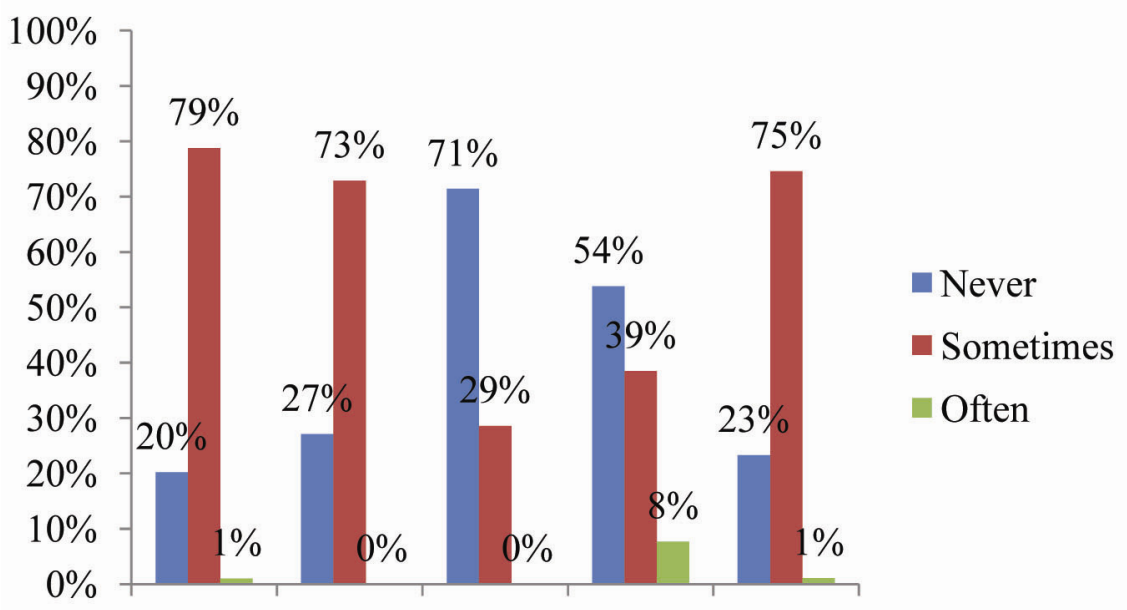

UDSM UDOM Tumaini St Johns Overall

Figure 2. Percentage of respondents reporting having experience physiological related forms of stress $(\mathrm{N}=284)$.

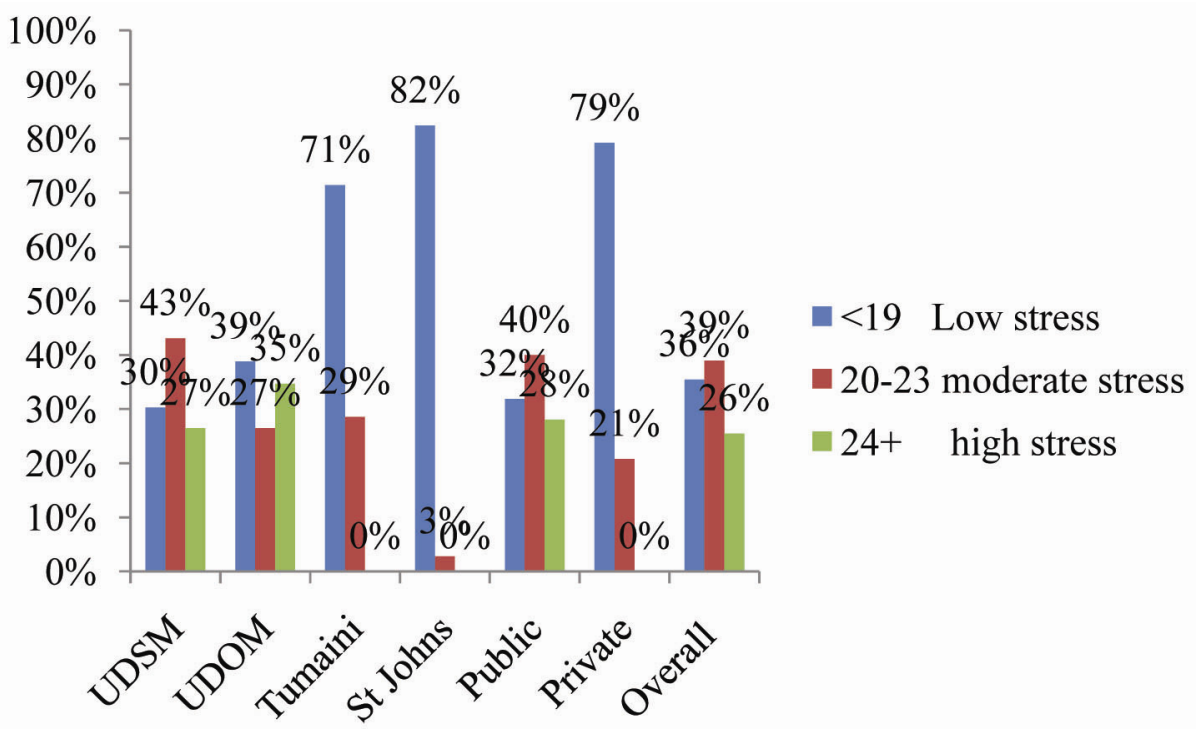

Figure 3. Percentage of respondents reporting low, moderate and high levels of physiological stress $(\mathrm{N}=284)$ 


\subsubsection{Psychological (work) stress}

Eight items were included in the questionnaire for assessing the level of psychological stress. Respondents were asked to indicate whether they ever felt 'irritated, angry, frustrated, helpless, anxious, depressed, unable to concentrate and over tired' while working. There were three response options: 'never', 'sometimes' and 'often'. The responses are summarised in Figures 4 and 5.

Overall, as Figure 4 shows, 83 percent of respondents reported having ever experienced some form of psychological stress while working. Eighty nine percent of respondents at UDSM and 86 percent at UDOM reported 'sometimes' experiencing psychological stress while working. For private universities, 63 percent of the respondents at Tumaini and 44 percent at St Johns reported experience psychological stress while working.

Overall, being 'overtired' was the most frequently reported psychological stress by the majority of respondents; 20.8 percent of the respondents reported often being overtired while working. For private universities, a significant proportion of respondents also experienced being 'helpless'; 12.9 percent of the respondents in private universities reported often feeling helpless while working.

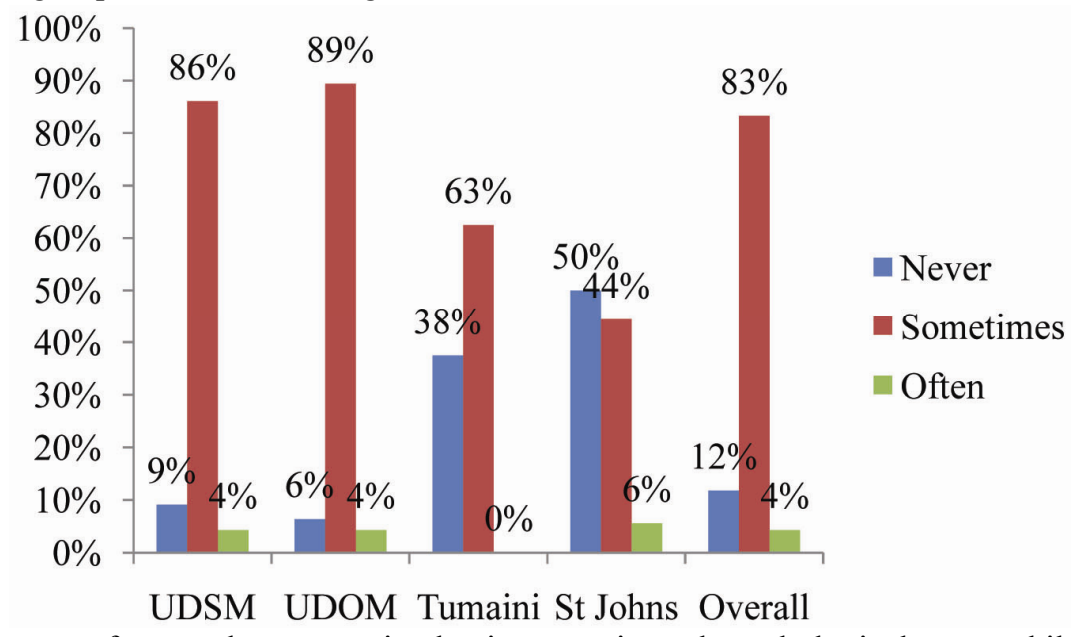

Figure 4. Percentage of respondents reporting having experienced psychological stress while working $(\mathrm{N}=282)$.

As Figure 5 shows, overall, 18.4 percent of the respondents reported being psychologically highly stressed, while 46.5 percent reported being psychologically moderately stressed. The highest proportion of respondents reporting being psychologically highly stressed came from UDOM (25\%), followed by UDSM (20.6\%). There was a statistically significant difference in the level of psychological stress between institutions: $\mathrm{X}^{2}(282,6)=23.82, p=.001$, $P h i=.21$. There was also a statistically significant difference in the level of psychological stress between public and private universities, with a higher proportion of respondents in public universities reporting high psychological stress than respondents in private universities: $\mathrm{X}^{2}(282,2)=19.42, p<.00005$, Phi=. 26.

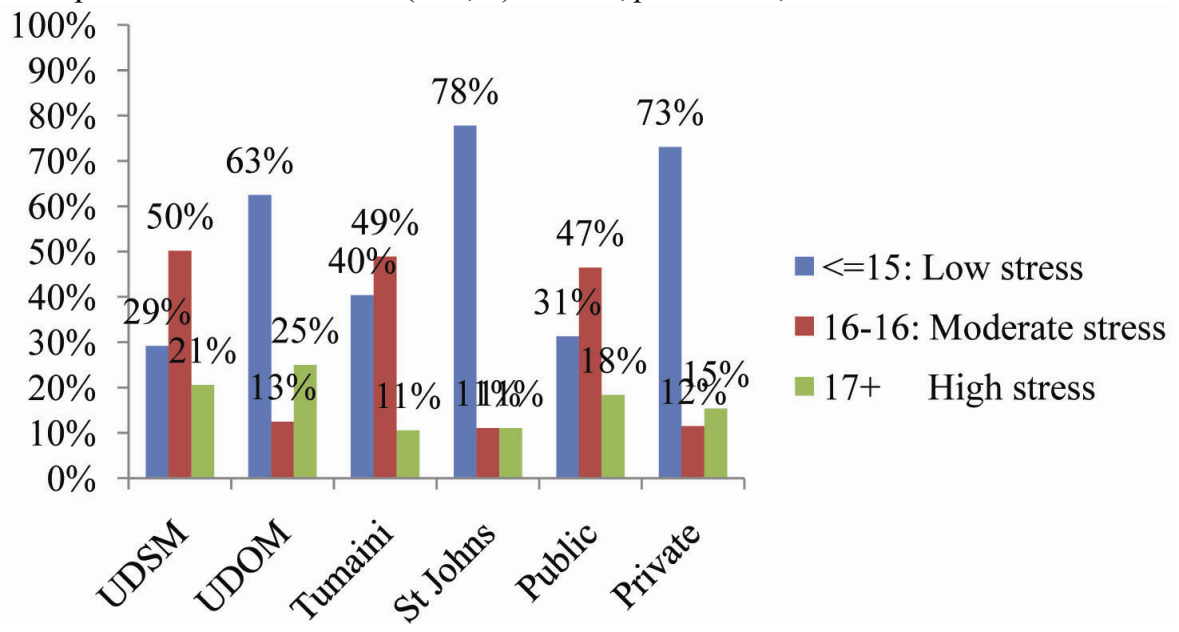

Figure 5. Percentage of respondents reporting low, moderate and high levels of psychological stress( $\mathrm{N}=282)$ 


\subsection{Relationship between work stress and job satisfaction}

The physiological stress and psychological stress scores were computed to get an overall stress score. The mean stress score was $36.4(\mathrm{SD}=5.57)$, indicating a moderate stress level. On average, 30.1 percent of the respondents reported being highly stressed, with UDOM having the highest respondents (39.5\%) reporting being highly stressed, followed by UDSM (30.9\%). The private universities had the lowest proportion (less than 5 percent) of respondents reporting being highly stressed (see Figure 6).

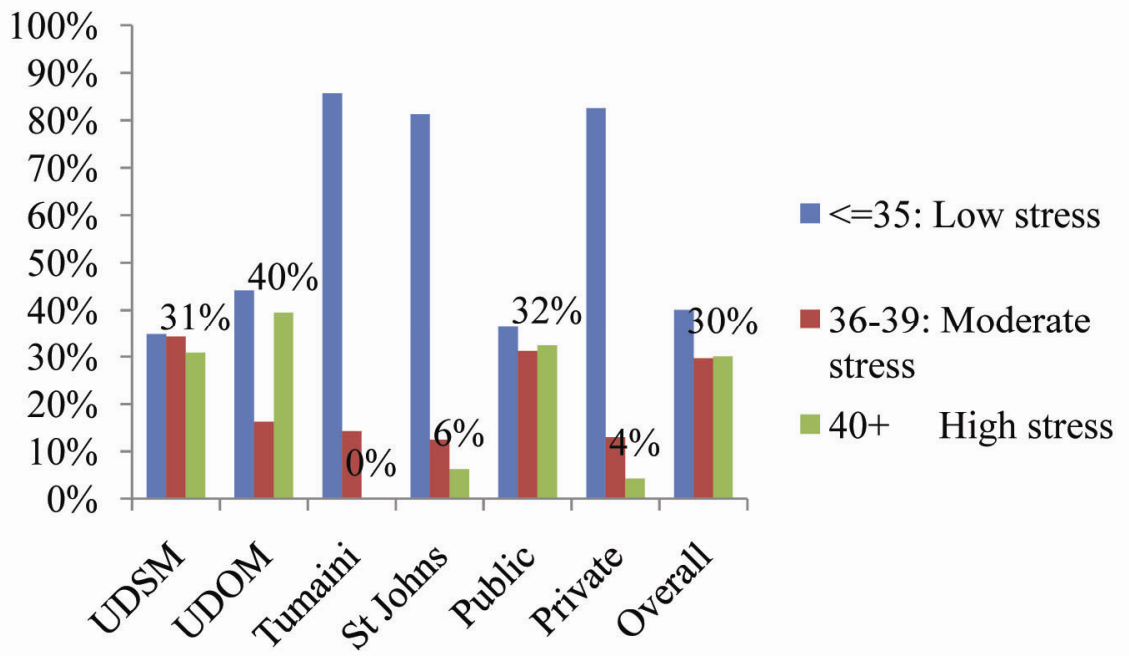

Figure 6. Percentage of respondents reporting being lowly, moderately and highly stressed $(N=273)$

The relationship between physiological stress and psychological stress was examined using Pearson product-moment correlation coefficient. Preliminary analyses were performed to ensure no violation of the assumptions of normality, linearity and homoscedasticity. There was a medium, positive statistically significant correlation between the two variables, $\mathrm{r}=.40, \mathrm{n}=279, \mathrm{p}<.0005$, with high levels of physiological stress moderately correlated with high levels of psychological stress.

When stress level was correlated with job satisfaction, the results showed that there was a small, positive statistically significant correlation between the two variables, $\mathrm{r}=.02, \mathrm{n}=316, \mathrm{p}=.02$.

\subsection{Factors causing stress in academia}

The UK Health and Safety Executive (HSE, 2006) identifies six areas with potential hazards that may lead to stress, namely demands, control, support, relationships, role and change. The demands aspect includes such matters as workload, work patterns and the work environment. Control looks at how much people in an organization have say in the way they do their work. Support deals with issues related to the availability of social support systems, such as the encouragement, sponsorship and resources provided by the organization, line management and colleagues. Relationships look at how much members of the organization promote positive working to avoid conflict, and in dealing with unacceptable behaviour such as bullying. The aspect on role looks at how much members of the organisation understand their role within the organization and how much the organisation ensures that they do not have conflicting roles. Change looks on how organizational change (large or small) is managed and communicated in the organisation.

In order to assess the extent to which the above factors were contributing to vulnerability to stress, respondents were given several scenarios and asked to indicate how much they agreed or disagreed with such scenarios. There was a total of 41 scenarios altogether.

Overall, as Figure 7 shows, the majority of respondents reported being able to handle and manage the demands of their jobs successful. For example, 91.8 percent of the respondents either strongly agreed or agreed with the statement that I am able to cope with the demands of my job, and 80.2 percent of the respondents either strongly agreed or agreed with the statement that there are proper systems to respond to any concerns that I may have. The respondents, however, reported that they could not cope with three aspects of their job demands. For example, 77.7 percent of the respondents either strongly agreed or agreed with the statement that in my institution, there are frequent changes to timetable or courses. Furthermore, 80.9 percent of the respondents either strongly agreed or 
agreed with the statement that over the past 2-5 years, my workload has increased. Again, 84.7 percent of the respondents either strongly agreed or agreed with the statement that I am always compelled to hit targets/deadlines.

The majority of respondents felt that they were in control of the situations in their universities. For example, more than 80 percent of the respondents either strongly agreed or agreed with the statements that $I$ have a say about the way I do my work, I participate in decision making and I am able to plan my working day. The trend was the same for relationships and job role, with the exception of one aspect of job role (pay prospects). Only 36 percent of the respondents strongly agreed and agreed with the stamen that my job has good pay prospects, implying that pay prospect was not one of the motivating factors for the majority of the academic staff members.

Change and support were the lowly rated aspects in which academic staff had control over. Overall, less than 60 percent of the respondents reported that they were in control of the changes taking part in their institutions. Even less respondents felt that there were adequate support systems to support their job in their respective institutions. For example, only 46.7 percent of the respondents strongly agreed and agreed with the statement that employees know how to access the required resources to do their job, and only 42.2 percent of the respondents strongly agreed and agreed with the statement that there were adequate opportunities to access training. Only 41.5 percent of the respondents strongly agreed and agreed with the statement that $I$ have adequate access to important facilities, such as photocopiers.

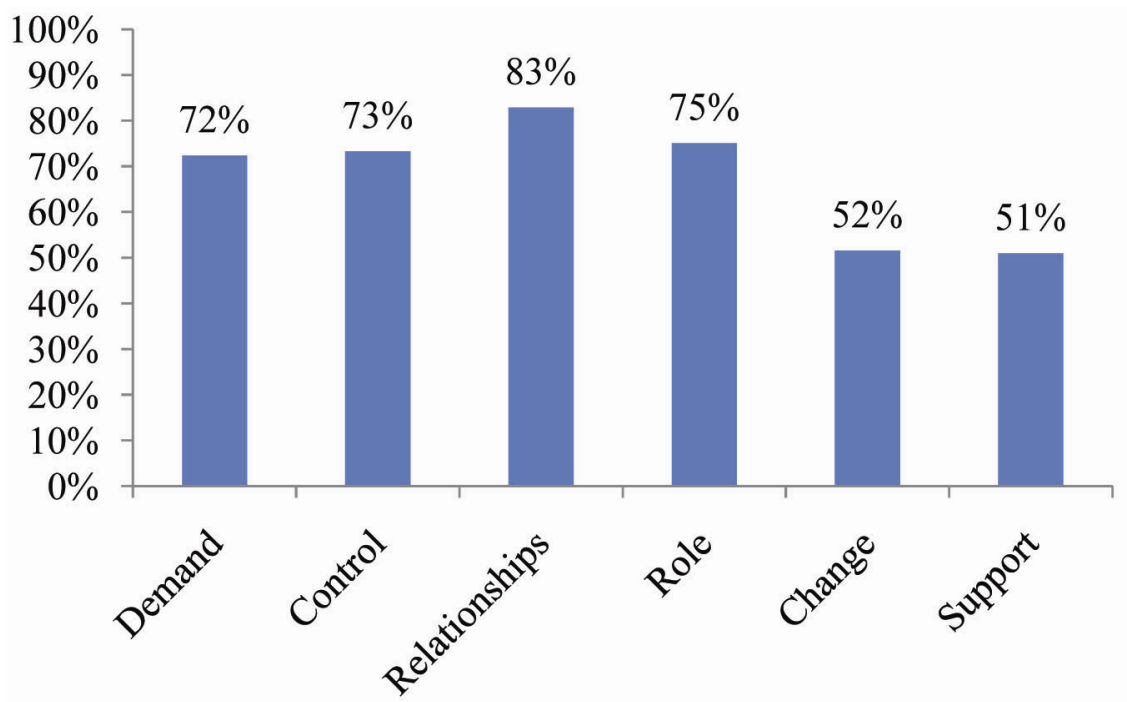

Figure 7. Percentage of respondents reporting being in control of the various situations in their universities

When the results on the factors causing stress were analysed with respect to institutions, a statistically significant higher proportion of the respondents at the University of Dar es Salaam reported being in control of the various situations in their institution than their counterparts in other universities (see Table 2). For example, while 84.5 percent of the respondents at UDSM reported being in control of the demands of their job in their institutions, only 32.1 percent at UDOM and 22.2 percent at Tumaini Universities reported as such. A considerably higher proportion (78.6\%) of respondents at the St Johns University also felt that they were in control of their job demands. Overall, a far higher proportion of respondents in public universities reported being able to manage their job situations in their institutions compared to their counterparts in other universities (see Figure 9). This implies that academic staff in other universities are potentially more vulnerable to work stress conditions than those at the University of Dar es Salaam.

Table 2. Percentage of Respondents Reporting being in Control of the Various Job Situations in their Universities

\begin{tabular}{cccccc}
\hline Aspect & UDSM & UDOM & Tumaini & St Johns & $\boldsymbol{p}$ \\
\hline Demand & 84.9 & 32.1 & 22.2 & 78.6 & $<.0005$ \\
Control & 87 & 40 & 50 & 42.1 & $<.0005$ \\
Relationships & 93.7 & 46.1 & 72.5 & 68.8 & $<.0005$ \\
Role & 86.2 & 39.6 & 42.9 & 61.9 & $<.0005$ \\
Change & 61.3 & 28.1 & 20 & 31.3 & $<.0005$ \\
Support & 56.9 & 38.1 & 30 & 47.7 & .002 \\
\hline
\end{tabular}




\section{Summary and conclusions}

The results of this study show that a significant proportion of members of academic staff who completed the questionnaire reported having experienced both physiological and psychological types of stress. About a quarter of the respondents reported being highly physiologically stressed, and 18.4 percent reported being highly psychologically stressed. Respondents in public universities seemed experiencing more stress than their colleagues in privately owned universities.

When physiological stress and psychological stress scores were combined to compute an overall stress level, it emerged that about a third (30.1\%) of the respondents seemed experiencing high levels of stress, with the majority of the respondents being at UDOM (39.5\%) and UDSM (30.9\%). Stress and job satisfaction were positively correlated, with the implication that highly stressed people may not enjoy their jobs as well as those who are lowly stressed.

Several factors seem to be causing stress or exposing members of universities to potential stress. These include the workload levels. The mean reported number of working hours was 58.2 hours, with staff at the University of Dar es Salaam reporting working for a mean of about 77 hours. This workload is far beyond the workload prescribed in the Tanzania 2004 Employment and Labour Act, which states that the normal working hours per week for an employee is 48 hours. This means that staff at UDSM work for more than 30 hours (more than 60\%) on and above the legally recognized number of hours in a week. Furthermore, the majority of respondents reported that their workload had increased considerably in the past two years. Thus, workload in institutions of higher education is one potential source of work stress that needs to be addressed. This is particularly the case with staff in public universities, and especially those at the University of Dar es Salaam.

Several other factors were examined with respect to their contribution to triggering stress among members of academic staff, including demand, control, relationships, role, change and support. Only a few respondents reported being effectively informed and involved in the changes that may be happening in their institutions. Similarly, only a few also reported that the support systems in their institutions were facilitative in their work. This implies that these two areas were a potential contributor to stress among members of staff. It was control, however, that revealed a statistically significant association with stress, indicating this aspect was a potential factor in causing stress among members of academic staff.

On the basis of the results of this study it can be concluded that members of academic staff in institutions of higher education in Tanzania are vulnerable and susceptible to both physiological and psychological stress. Workload, lack of control and say in what is happening in their institutions and lack of necessary support systems related to their work are the most significant factors that make staff in institutions of higher education vulnerable to stress.

\section{References}

Abouserie, R. (1996). Stress, coping strategies and job satisfaction in University Academic staff. Educational Psychology, 16, 49-56. http://dx.doi.org/10.1080/0144341960160104

Ahsan, N., Abdullah, Z., Fie, D.Y.G., \& Alan, S.S. (2009). A study of job stress and job satisfaction among university staff in Malaysia: Empirical study. European Journal of Social Sciences, 8, 120-131.

Ayers, S., McManus, C., Baum, A., Newman, S., Wallston, K., Weinman, J. et al. (2007). Cambridge handbook of psychology, health and medicine.Cambridge University Press.

Barlett, J.E., Kotrilik, J.W., \&.Hignins, C.C. (2001). Organisational research: Determining appropriate sample size in survey research. Information Technology, Learning, and Performance Journal, 19, 43-50.

Blaud, R., Kenyon, A., \& Lekhi, R. (2007). Stress at work: A report prepared for the Work Foundations' principal partners. London: The Work Foundation.

Blix, A.G., Cruise, R.J., Mitchell, B.M. \& Blix, G.G. (1994). Occupational stress among university teachers, Educational Research, 36, 2, 157-169. http://dx.doi.org/10.1080/0013188940360205

Court, S., \& Kinman, G. (2008). Tackling stress in higher education. [Online] Available: http://www.ucu.org.uk/media/pdf/8/a/ucu_hestress_dec08.pdf

Davey, J., Obst, P., \& Sheehan, M. (2001). Demographic and workplace characteristics which add to the prediction of stress and job satisfaction within the police workplace. Journal of Police and Criminal Psychology, 16, 29-39. http://dx.doi.org/10.1007/BF02802731

Dunham, J. (1992). Stress in teaching (2 ${ }^{\text {nd }}$ edition). London: Routledge. http://dx.doi.org/10.4324/9780203314500

Fisher, S. (1994). Stress in Academic Life: The Mental Assembly Line, Buckingham: SRHE. 
Galloway, D., Panckhurst, F., Boswell, K., Boswell, C., \& Green, K. (1987). Sources of stress for primary head teachers in New Zealand.British Educational Research Journal, 12, 281-288. http://dx.doi.org/10.1080/0141192860120306

Health and Safety Executive. (2006). Investigation of the links between psychological ill health, stress and safety. Norwich, UK: Crown.

Ismail, A., Yao, A., \& Yunus, N.K.Y. (2009). Relationship between occupational stress and job satisfaction: An empirical study in Malaysia. The Romanian Economic Journal, 4, 3-22.

Kahn, R.L. (1974). Conflict, ambiguity, and overload: three elements in job stress. In A. Maclean (Ed.) Occupational Stress, Thomas: Illinois.

Maslach, C., Schaufeli, W.B. \& Leiter, M.P. (2001). Job burnout. Annual Review of Psychology, 52, 397-422. http://dx.doi.org/10.1146/annurev.psych.52.1.397

Nhundu, T.J. (1999). Determinants and prevalence of occupational stress among Zimbabwean school administrators. Journal of Educational Administration, 37, 256-166. http://dx.doi.org/10.1108/09578239910275490

Pallant, J. (2005). SPSS survival manual (2 ${ }^{\text {nd }}$ ed.). Berkshire, UK: Open University Press.

Palmer, S., \& Cooper, C. (2007). How to deal with stress. London: Kogan Page.

Phillips, S., Sen, D., \& McNamee, R. (2007). Prevalence and causes of self-reported work related stress in head teachers. Occupational Medicine, 57, 367-376. http://dx.doi.org/10.1093/occmed/kqm055

Redhwan A.A.N., Sami A.R., Karim A.J., Chan, R., \& Zaleha M.I., (2009). Stress and coping strategies among Management and Science University students: A qualitative study. International Medical Journal, 8, 11-15.

Smith, A., Brice, C., Collins, A., Matthews, V., \& McNamara, A. (2000). The scale of occupational stress: A further analysis of the impact of demographic factors and type of job. Norwich, UK: Crown.

Winefield, A., \&. Jarret, R. (2001). Occupational stress in university staff. International Journal of Stress Management, 8, 285-298. http://dx.doi.org/10.1023/A:1017513615819 